\title{
TEACHING DESIGNERS' ENTREPRENEURSHIP: MAPPING STUDENT DESIGN PROCESS OF LEAN START-UP AND EFFECTUATION
}

\author{
Thien Quang TRAN and Linda Nhu LAURSEN \\ Aalborg University, Rendsburggade 14, 9000 Aalborg
}

\begin{abstract}
Recent studies show entrepreneurs tend to prioritize either the business or the design side of their startup, as combining design and entrepreneurship may represent a dual focus and tension in the development process. However, it is commonly recognized that both needs to be developed to become a proficient design-based entrepreneur.

In the following paper we examine an exemplary case of design-based entrepreneurship. We study a case of how industrial design master's students from Aalborg University, may develop an integrated design and entrepreneurial approach to solve a dual design and business challenge. By using theories and a mindset of effectual reasoning combined with the lean start-up approach, a design based entrepreneurial approach was mapped out.

We use this case not only to study similarities and differences between the design approach and the entrepreneurial approach, but also to understand key elements in how to integrate on one another in an educational setup.
\end{abstract}

Keywords: Design education, effectuation, lean start-up, design processes

\section{INTRODUCTION}

Within the last decades entrepreneurship has received an increasing focus and interest in practice as well as in the university curriculum. Research shows many creatives and designers are more likely to become entrepreneurs at one point in their career [1]. However, as Tötterman mentions, there is evident that there are many design entrepreneurs who lacks the needed business competencies in relation to administration, marketing and operations [2]. This provides a challenge of how to integrate the trades of the entrepreneurial discipline in the design education.

In design education, there is a long practical tradition for immersing in design projects that evolve around physical, emotional and social aspects. Aspects such as user research, materials, form and production are fundamental pillars of many industrial design educations. However, to become a skilled designer today, it is also important to consider the business context, which a design is to emerge in. However, studies show combining design and entrepreneurship may represent a dual focus and tension in the development process. Entrepreneurs tend to priorities' either the business or the product side, despite it is commonly recognized that both needs to be developed to a matured degree to become proficient design-based entrepreneurs [3].

This study builds upon a recent educational course [4], which emphasizes the execution and action aspects of the design process. The students are given a challenge to design, produce and promote 20 units of any product in 15 workdays and at the end sell it at a fair. From this layout we deploy an information-oriented selection strategy, to identify and examine an exemplary case of an integrated design and entrepreneurial development process. We deploy such purposeful sampling, in which we select an information-rich case, to enlighten the question of interest, rather than representing a broader population [alike 5]. Our aim is to select an exemplary case of design-based entrepreneurship to map out activities and processes, that may help integrate entrepreneurial elements into design education. Hence our study aims to understand how to integrate entrepreneurial elements in a design process.

This paper show that Industrial Design Engineer master's students can act as entrepreneurs and utilize both an entrepreneurial and design-based process by applying simple principles and methods from the effectuation approach [6] and lean start-up [7]. By doing so, we force designers away from a primary 
user and desirability focus (expressed as thought representations e.g., sketches, renderings, posters), and instead focus on doing realisable design, thus giving designers a feeling of ownership of all aspects of their product including design, production, business, market and resource issues. To succeed in this course, the students have to integrate elements from both Design Thinking with elements from Effectuation and lean start-up. The study shows they may be able to operate confidently within design execution phases, by doing and shaping the future instead of trying to predict it (Effectuation); as well as making quick market research checks and pivots (lean start-up). Effectuation is a direct contrast to causal logic, where you in the beginning already set a goal and the process to achieve this goal is carefully organised in accordance with a set of given resources, but this cannot be applied in Effectuation processes, since it is inherently characterized by uncertainties and risks [6].

In the following we will layout the educational setup, then provide an overview of the students' design based entrepreneurial process overview.

\section{THE EDUCATIONAL SETUP}

On the $2^{\text {nd }}$ year master's of Industrial Design Engineering the students attend this course, where the learning goal is to further accelerate product development and drive business focus, hence integrating and consider the business/entrepreneurial aspects in the design process and outcome [4]. The task is given: "Design, produce and promote 20 units of any product in 15 workdays and at the end sell it at a fair." [4]

The rationale behind such task was to make students consider both the design, production, business, market and resource aspects already from the beginning. The idea behind the limited time of 15 days, was students were required to develop these aspects in parallel and or rapidly iterate between them. In the following we first give an overview of the process, to discuss and later reflect upon how it may contribute.

\section{DESIGNS BASED ENTREPRNEURIAL PROCESS OVERVIEW}

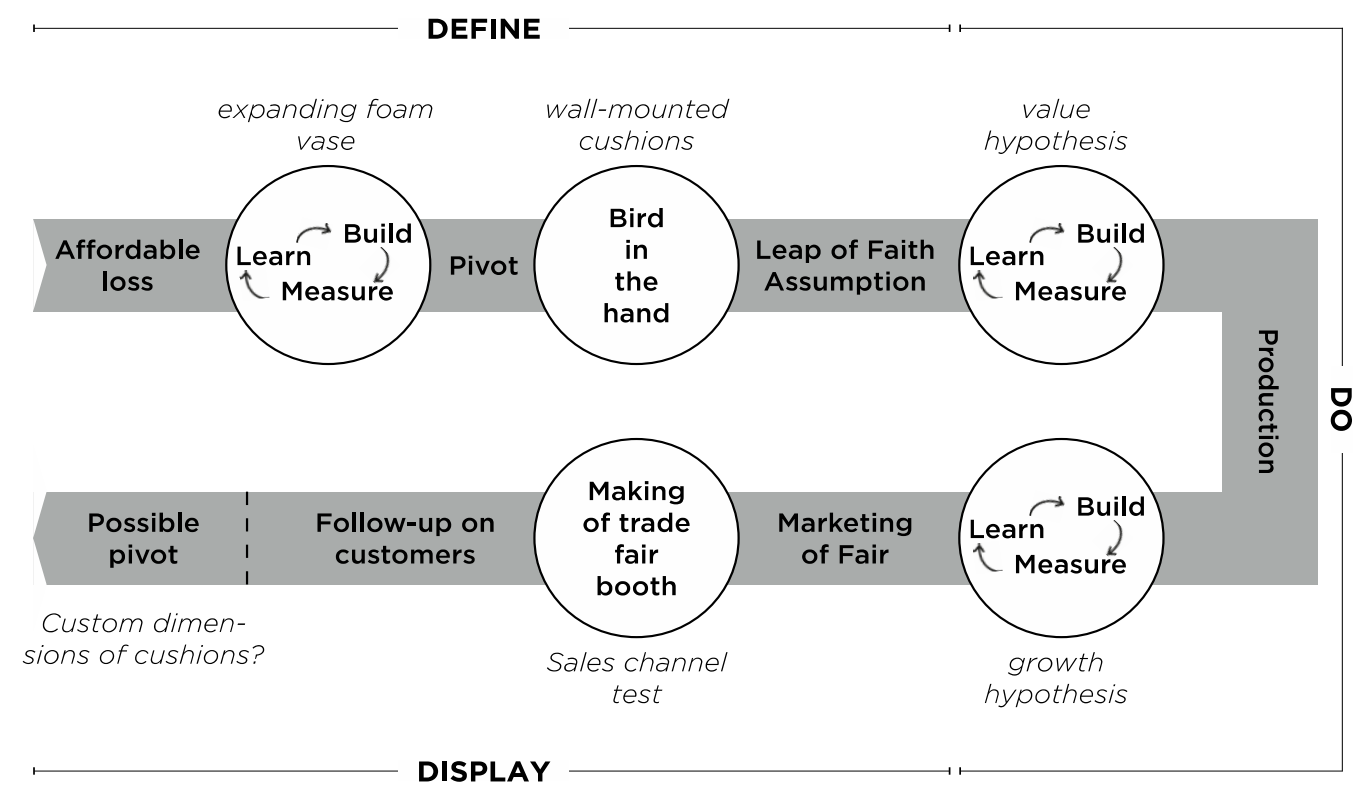

Figure 1. Define-Do-Display process overview

The above figure illustrates the overall process overview, of which it is clear that the build-measurelearn feedback loop [7] is frequently used, but in three different scenarios and purposes. This, together with the rest of the development process, will be addressed with exemplary dives in the following sections. 


\section{HOW A NATURAL DESIGN ENTREPRENEUR APPLIES METHODS FROM EFFECTUATION AND LEAN START-UP}

\subsection{Fail early, fail often, fail forward}

In the beginning of the project of making 20 units of a product that was supposed to be sold on a fair within 15 workdays, it was clear that the team had to commit to an Effectuation approach [6] and develop an actual MVP (Minimal Viable Product) [7] as fast as possible. An MVP is a core component of lean start-up and is part of how to figure out the problem that needs to be solved to begin learning in the early phases.

By quickly and early on in the process committing to the build-measure-learn feedback loop [7], the team only ideated shortly on possible products to be build. Build-measure-learn is one of the central principles of lean start-up and is in short "a framework for establishing - and continuously improving - the effectiveness of new products, services and ideas quickly and cost-effectively" [7]. In practice it revolves around building something small for potential customers to try and test followed by measuring the feedback and their critique to finally learn from it and then continuously repeat the process to ultimately deliver precisely what your customer wants and needs. Instead of endlessly generating one idea after another, the team chose an idea in which was cheapest, easiest and fastest to make an MVP of. The team wanted to tap into the DIY-trend at that moment and quickly went on Pinterest to find pictures of a PU-foam vase which met the criteria of being a 'designer-product'. The goal was to be able to produce a product fairly cheap and fast while in the end possibly being sold at a higher price. A quick and dirty prototype was made. Unlike in e.g., the Design Thinking process presented by Stanford d.school where stages like emphasize, define and ideate comes before prototyping - which is typically not until in this stage that user involvement is considered in the product development. Of course, in design you also evolve the product development through various iterations, and it is recognized that 'prototyping' is also applied early on in the design process, but language wise it is called something else - for instance sketches, mock-up's, wireframes and for another purpose.

Producing an MVP in the early phase made it possible to move quickly onto validating the value hypothesis [7], which was performed by using both a digital platform (Instagram Stories) and an analogue multiple-choice test to get as much data as fast as possible. The first mentioned was made by three so-called 'Stories' (a feature that lets users post photos and videos that vanish after 24 hours). The first two Stories presented the vase in its intended context with a short description (key-selling-points), the third and last one invited the viewer to make a decision on the Story - the viewer was asked to vote either 'yes' or 'no' on whether he/she could imagine owning a vase like that. 140 people saw the Stories and $92 \%$ voted 'no'.
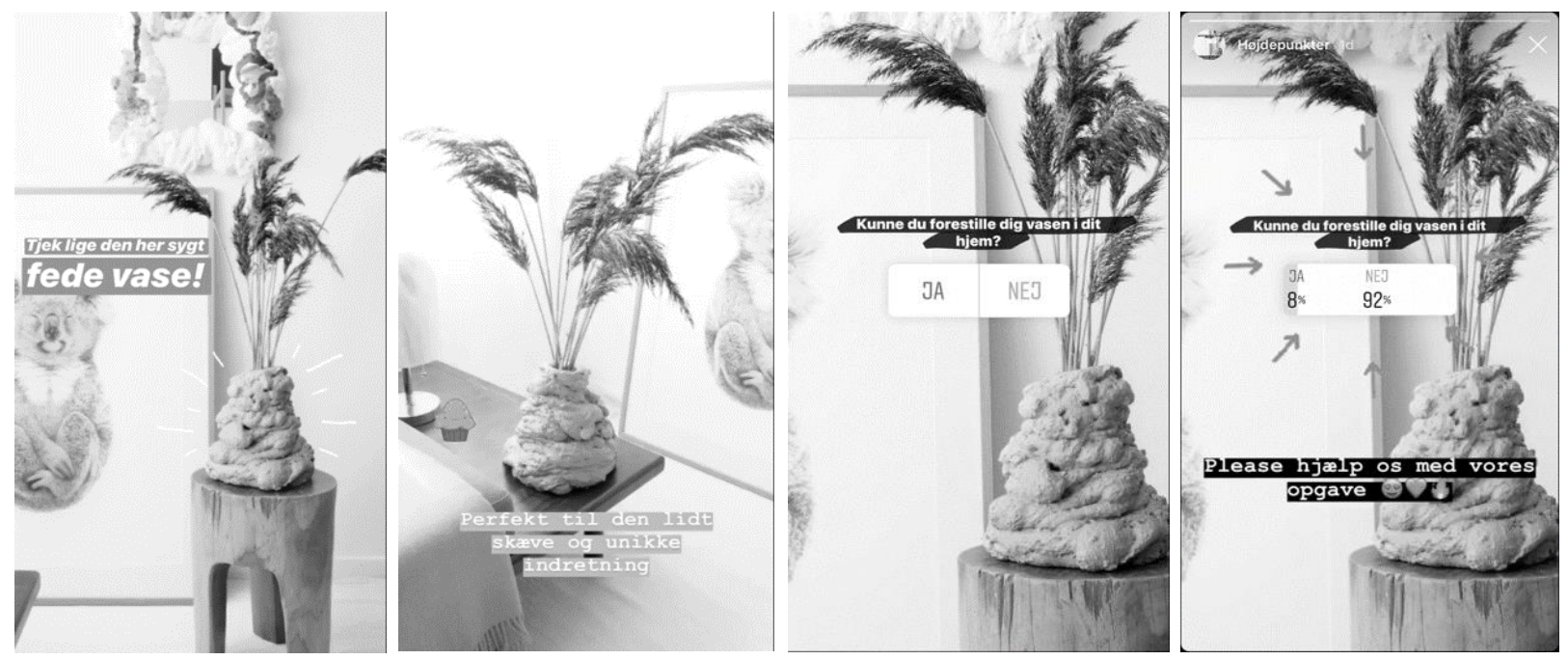

Figure 2. Screenshots of the foam vase used to probe the customers

The team learned from the data collected, which clearly did not show an immediate interest in the product but gave the team an idea of what kind of people the analogue multiple-choice test should target. When students post educational work on social platforms. They are confronted with 'real world' 
feedback, which may of course create both positive effects of students feel ownership of their design, being held personally accountable, however this may also negatively affect the safe learning environment.

The multiple-choice test verified and supported the same data from the digital test but gave the team additional statements about why the majority of people voted 'no'. Considering the time available at the moment, it was clear that the expanding foam vase was not worth doing further developments on, and the team chose to make a pivot [7], but with the 'failures' from the first build-measure-learn feedback loop in mind. Making a pivot is a "...structured course correction designed to test a new fundamental hypothesis about the product, strategy and engine of growth" [7]. From the first feedback loop, the team learned about how important an MVP is and that the answers received can never be better than the quality of the MVP.

Within three days, the team already went on to try and make another product from scratch, unlike in Design Thinking [8] where the potential reframing-process typically takes much longer time and the creation of a Design Thinker's correspondent to an MVP, a so-called prototype, would be made much later in the process. Besides these differences, there is also the difference between what the purpose of an MVP is contrary to a prototype (as known from Design Thinking Paradigme) [8]. An MVP is mainly used for business intentions whereas a prototype is mainly used to test functions, features and proof of concept.

\subsection{Validating a Leap of Faith Assumption (LOFA) by selling the product without even having it yet (call to action)}

The Leap of Faith Assumption describes the riskiest assumption there is about an idea [6]. It either breaks or makes your business. There are two kinds of assumptions, which are necessary to understand: value hypothesis and growth hypothesis [7]. A value hypothesis tests whether or not if a certain product actually delivers value to the potential customer, meaning that it determines if a customer should adopt a product into their lives or not [7]. A growth hypothesis comes after you have managed to provide value to the customer with a product and is about how customers find your product and how the company behind it will grow once customers begin using the product [7]. After the team found out that the expanding foam vase did not work as intended, they used the bird in the hand principle [6], to get a grasp of what was mostly reasonable to do at that moment. The team listed the three categories of means: (1) Who they are, (2) What they know and (3) Whom they know - which created a lot of possible imagined ends. By forcing the team to think with an effectuation approach, the set of means listed allowed goals to emerge contingently over time from the varied imagination and diverse aspirations of the team members and the people they interact with [6].

The team suggested using one's father's workplace (a textile and foam factory) as a way to get cheap raw resources (fabric, cold foam and buttons), and this resulted in a spark in the other team member suggesting producing a wall-mounted cushion which he once had in his apartment. Instead of making a lot of assumptions of whether or not it was a good idea, the team decided quickly just to do something. And that something was to re-activate the online sales ad of which one of the group members once had and was now granted permission to start a conversation to everyone who firstly approached him and asked if the item was available. At that moment, the value hypothesis was already validated by a picture of a wall-mounted cushion that the team did not even have produced yet, since the team sealed the deal with the majority of the people who were asked, if they were still interested in buying the product. By doing this, the risk of the assumption about if there was a market for it or not was indeed removed, and the team could focus on producing the product in 20 units without worrying about the investment returning to them or not.

In retrospect, the team learned that the customers who said yes to buy the product were 'existing' customers who already showed interest in the sales ad back when that group member first put them up as his own private sales ad in the area of Aalborg, Denmark. To test how new customers would discover the wall-mounted cushion (growth hypothesis) [7] they took new pictures of the newest produced cushions and made several new sales ads on the same digital platform as before, but in different locations too. Aarhus, Odense and Copenhagen were chosen because the team members were often at those cities anyways. It was about getting out to as many people as possible to sell 20 units as fast as possible, because they knew, that they would not sell any at the fair. This was based on the assumption of that the kind of segment the online sales ad was from, would most likely not attend the fair at the fixed opening hours and location. In contrary to the effectuation approach and lean start-up, where probing early on 
by involving the customer as soon as an MVP is made and trying to figure out whether or not there is a market, in Design Thinking the bird in the hand principle has some similarities, just in another matter. Designers uses their own understandings, experiences and preferences directly in the conceptualization process [9]. Furthermore, designers often reuse knowledge, solution principles and experience from previous projects as their starting point of reference for creating new and innovative solutions in a totally different industry [9]. Though there is a difference in how and when the value hypothesis is applied in Design Thinking as mentioned in section 3.1. However, there is a clear difference when it comes to growth hypothesis, which is not typically contemplated in Design Thinking, because it is more about problem solving at its core [4] than considering the business development aspects.

\subsection{Finding the right market, channel, and price is crucial}

Some of the reasons for not continuing the expanding foam vase project was that the team did not identify or hit the right market for it at first, and maybe also chose the wrong channel to display them and lastly, they also struggled with the RRP (recommended retail price) of the product. Most of the answers from the multiple-choice test showed that most people would not sacrifice that much money on a vase they could make themselves with even less money. By having these early experiences of a failed project in mind, the team went more strategically with their wall-mounted cushion project and hit correctly with both the right market, a promising sales channel and the RRP was neither too high nor too low. By using the bird in the hand principle (What they know from a former sales ad of an almost identical product as the newly produced wall-mounted cushions) together with the affordable loss principle, the right market to target was easily obtained. The bird in the hand principle was also used in terms of the first category, since one of the team members had a lot of experience and professional competencies within retail sales from his many years of seniority within the field. The understanding and experience he had, saved the team from a lot of unnecessary time spend by 'controlling the failures' and made a working business strategy fairly quickly and without a bigger investment. It was truly an effectuation approach they managed to use. Design wise it was visible on the finished product that the quality and finish of the product did not exceed what the two group members could manage and were capable of at that moment when it comes to manufacturing and production, but instead reflects the level of execution. 20 pieces were produced fairly quickly without any need of learning new production methods, since they used the competencies and know-how they had, instead of spending time on production methods they have not have any hands-on experience of before. For instance, none of the group members was an expert in sewing, so the corners of the cushions were just folded like gift wrapping and the fabric was clipped to the back of the cushion. These were well-considered choices, considering that it was not the normal way to upholster such a furniture accessory, because if the team chose to do so, the time and money spend on the cushion would grow exponentially and thereby also affecting the market and RRP, whereof they knew worked fine without doing so.

\section{CONCLUSIONS}

This paper is an example of how Industrial Design Engineer master's students can achieve a successful combination of effectual reasoning and lean start-up theories. Working with all these kinds of approaches in coherent with each other but knowing when to use what and to understand the differences and similarities was the most challenging part of the whole process from idea to finally selling the units. For instance, an Industrial Design Engineer is used to call the people that they design for as users, while in lean start-up they are called customers. They are to an extend the same person but interpreted in different ways. The word 'user' is in Design Thinking understood as someone who uses something and in the world of lean start-up, the word 'customer' is considered as someone who purchases something. This was also experienced from the beginning of the project till the end, whereas instead of seeking a problem to solve for a user, as one would typically do in Design Thinking, it was determined to seek for business potentials to target specific customers with the intention to run a feasible business.

The basic of both is innovation and looking at a methodological level they both also seem the same, in terms of first come up with an idea, then test and show it with/to others, prototype it, make sense of the feedback and finally adapt it until it solves the problem.

It is not because Design Thinking does not have business elements in it (e.g., the $6^{\text {th }}$ phase 'Implementation') but the focus is more on the user and desirability aspects, making many design products a bit detached from the business reality while in Effectuation and lean start-up it is about retaining current customers' businesses and solving immediate problems by familiarising through 
building, measuring, learning, repeat. Furthermore, it was also clear that one of the biggest differences of Design Thinking vs. effectuation approach and lean start-up is that the two last-mentioned are much more in the 'proof of business' stage than Design Thinking being more in the 'proof of concept' stage. But yes, there are many similarities as well, for instance the passion to understand how people use certain products or services in their specific environments, and then testing concepts through rapid prototyping and learn from it. Whether you choose to use the language given in Design Thinking, Effectuation or lean start-up they all build on the same foundation about generating revenue with an innovative new product or service that functions flawlessly and solves human problems.

\section{REFERENCES}

[1] Vesalainen J. and Pihkala T. (1999). Entrepreneurial identity, intentions and the effect of the push-factor. Academy of Entrepreneurship Journal, 5(2), 1-24.

[2] Tötterman (2008). From creative ideas to new emerging ventures - entrepreneurial processes among Finnish design entrepreneurs. PhD thesis, Hanken School of Economics.

[3] Jørgensen M. P., Vindeløv R. H. and Laursen, L. N. (2020). Educating product-based start-ups: Focusing on the business or the product? In DS 104: Proceedings of the 22nd International Conference on Engineering and Product Design Educatio, VIA University. Herning,

[4] Tollestrup C. (2019). Industrial design execution \& academic reflection in a three-week-package. In DS 95: Proceedings of the 21st International Conference on Engineering and Product Design Education (E\&PDE 2019), University of Strathclyde, Glasgow. 12th-13th September 2019.

[5] Laursen L. N. 2017. Matching to openly innovate with suppliers: The phenomenon of innovation summits.

[6] Sarasvathy Saras D. (2005). What Makes Entrepreneurs Entrepreneurial? University of Virginia - Darden School of Business.

[7] Reis E. 2011. The lean startup. New York: Crown Business, 27.

[8] Laursen L. N. and Tollestrup C. 2017 Design Thinking - a Paradigm Proceedings of the 21st International Conference on Engineering Design (ICED 2017): Glasgow, Scotland: Design Society. pp. 229-238.

[9] Laursen L. N. and Haase L. M. 2020, August. Reinterpreting Tradition to Digitalize: Framing the Design DNA of LEGO House. In Synergy: DRS International Conference 2020 (pp. 2011-2022). Design Society. 